Editorial

\title{
Afterword to the Issue "Adolescents in the Digital Age: Effects on Health and Development"
}

\author{
Daniel Romer ${ }^{1, *}$ and Michael Rich ${ }^{2}$ \\ ${ }^{1}$ Annenberg Public Policy Center, University of Pennsylvania, Philadelphia, PA 19104, USA; \\ E-Mail: dromer@asc.upenn.edu \\ ${ }^{2}$ Department of Pediatrics, Harvard University, Boston, MA 02115, USA; E-Mail: Michael.Rich@childrens.harvard.edu \\ * Corresponding author
}

Submitted: 19 April 2016 | Published: 16 June 2016

\begin{abstract}
The articles in this thematic issue suggest both opportunities and hazards for the health and development of adolescents in the digital age. We place these concerns in the context of improving health for young people in the US and elsewhere, and suggest that based on evidence uncovered to date, increasing digital connection may be having no less favorable than adverse effect on adolescents.
\end{abstract}

\section{Keywords}

adolescents; behavioral health; development; digital communication; mental health

\section{Issue}

This editorial is part of the issue "Adolescents in the Digital Age: Effects on Health and Development", edited by Dan Romer (University of Pennsylvania, USA).

(C) 2016 by the authors; licensee Cogitatio (Lisbon, Portugal). This article is licensed under a Creative Commons Attribution 4.0 International License (CC BY).

This thematic issue highlights both opportunities and hazards for adolescents in the digital age. Although it is common to emphasize the hazards more than the benefits (see George \& Odgers, 2015), it is also important to recognize that on a variety of health indicators, young people are healthier today than before the digital age. Looking at recent trends in the US, use of major drugs of dependence has declined since their peak in the 1970's (Figure 1). Adolescent birth rates have declined (Figure 2), and deaths due to all forms of violence have remained the same for females and declined for males (Figure 3). Deaths from motor vehicle crashes have been on the decline (Figure 4). Although adolescent suicide rates have risen since 2007 in concert with the 2008 economic crisis (Figure 5), this trend has affected a wide age range in the US, suggesting that adolescents do not appear to be at unique risk (Curtin, Warner, \& Hedegaard, 2016).

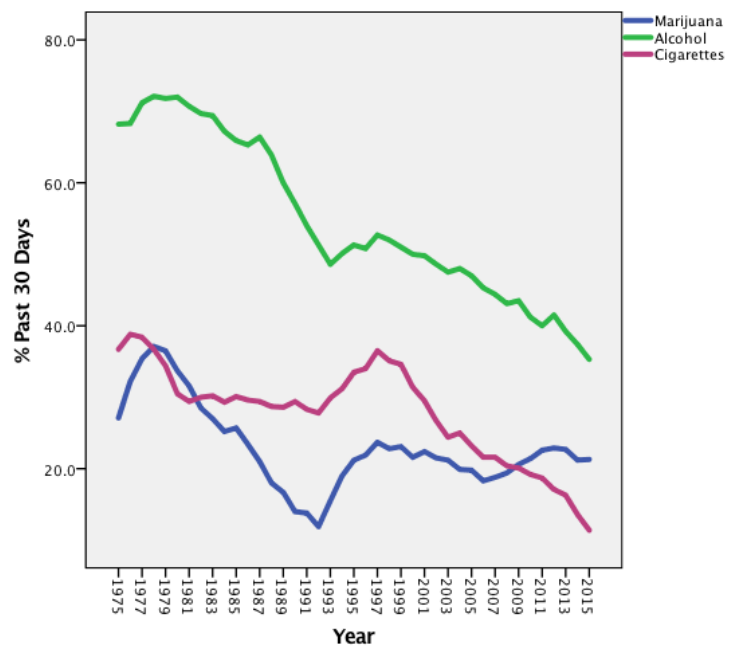

Figure 1. Rates of drug use by US high school $12^{\text {th }}$ graders based on the Monitoring the Future study. Source: Johnston, O'Malley, Miech, Bachman and Schulenberg (2016). 


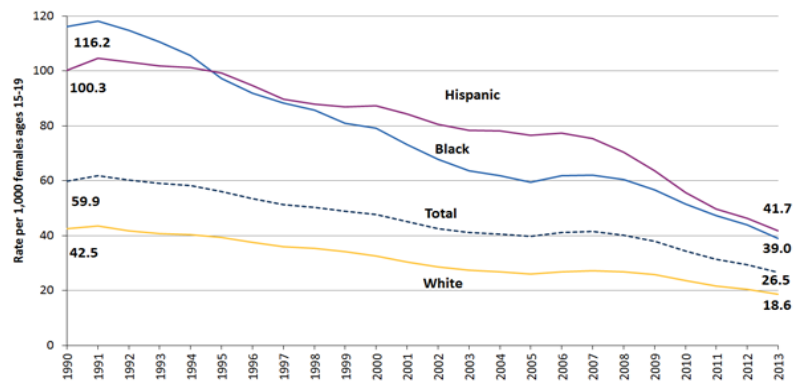

Figure 2. Birth rates to adolescents ages 15-19 in US from 1990-2013. Source: Office of Adolescent Health (2016).

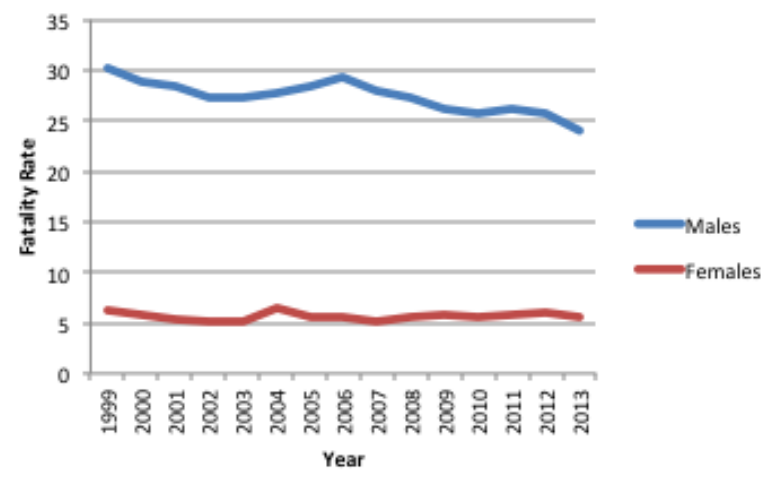

Figure 3. Rates per 100,000 of violent fatalities, including homicide and suicide from 1999 to 2013 in US. Source: Centers for Disease Control and Prevention (2016).

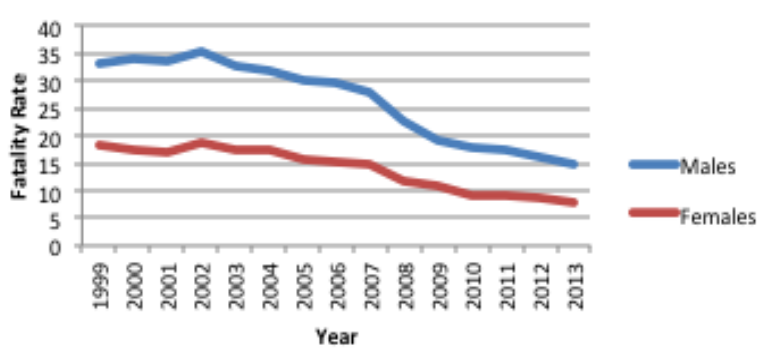

Figure 4. Rates per 100,000 of motor vehicle deaths in adolescents from 1999 to 2013 in US. Source: Centers for Disease Control and Prevention (2016).

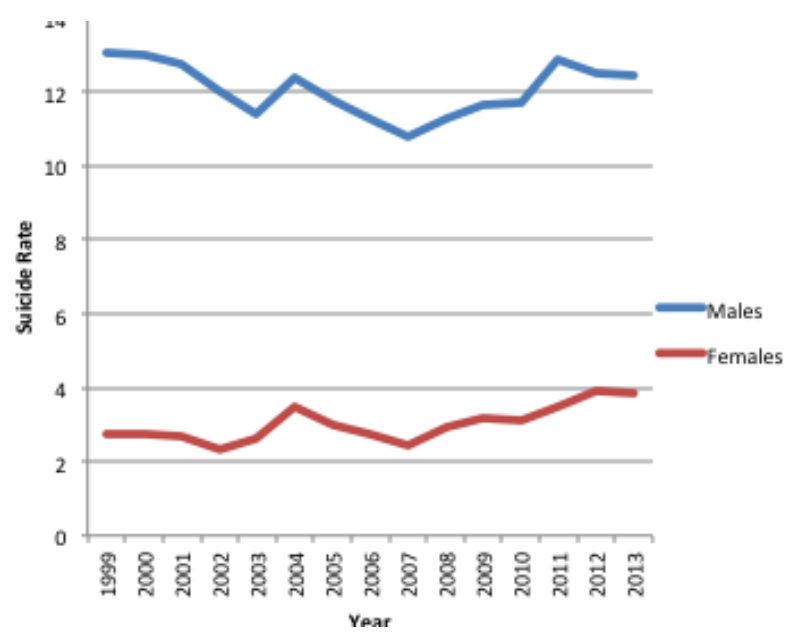

Figure 5. Rates per 100,000 of suicide deaths in adolescents from 1999 to 2013 in US. Source: Centers for Disease Control and Prevention (2016).
At this broad level, there is little to suggest that enhanced digital connectivity has altered the mostly favorable trajectories of adolescent health in the US. A recent review of the health of children and adolescents in the UK similarly found that indicators of mental and behavioral health problems have either remained the same or declined in recent years (Hagell, Coleman, \& Brooks, 2016). According to the Good Childhood Report (Pople, Rees, Main, \& Bradshaw, 2015), adolescents in the UK have reported steady levels of overall wellbeing from 2009 to 2013. Thus, in both the US and the UK, epidemiological trends in adolescent health do not correlate significantly with greater digital connectivity over the past 20 years. This finding is consistent with the observation that, while greater digital connectivity has dramatically changed adolescents' lifestyles, those changes may not have affected health for the better or for the worse.

As noted in the review by Mills (2016) adolescents today are using digital communication to enhance their connection with friends in the offline world. In a national study of US adolescents conducted by Dunlop, More and Romer (2011), they found that although users of social networking sites were more likely to be exposed to stories about someone they knew who either attempted or died by suicide, increased awareness of suicide did not lead to greater suicidal ideation. It is conceivable that the social support provided by others on social media can be protective against self-harm and suicide. Use of online forums, however, predicted increases in suicidal ideation. This is consistent with Mills' review (2016) suggesting that users of social networking sites are, on average, better adjusted than those who shun such sites, but that users who are troubled are at greater risk for bad experiences in online interactions with strangers. Nevertheless, some health promoting uses of the internet and social media have allowed previously marginalized or isolated youth to connect, communicate, and build community, as has been seen with sexual minorities (e.g., Rattan \& Ambady, 2014; Tropiano, 2014). At the same time, the rise of pro-ana and pro-mia eating disorder sites illustrates how some uses of the internet have supported dysfunctional behavior (Borzekowski, Schenk, Wilson, \& Peebles, 2010; Peebles et al., 2012; Wilson, Peebles, Hardy, \& Litt, 2006). As dramatically as digital media have changed how adolescents live and communicate with peers and the world, it is possible that those changes have not translated into overall greater risks to health. We may be witnessing how adolescent behaviors that previously played themselves out in the offline world are now migrating to the digital environment, which may increase some health risks and attenuate others

Again on the positive side, the internet has provided adolescents with greater opportunities to access health information in a private, controllable setting. As 
documented by Wartella and colleagues (2016), adolescents are using digital resources to access information about their bodies, health, and wellbeing. What is less clear is whether the information they are acquiring is leading to improvements in their health. Poor youth continue to experience barriers to accessing health information as well as health care in the US, reflecting the persistence of the digital divide and adding further urgency to the need to close the gap between the "haves" and the "have-nots". Recent efforts by the US Federal Communication Commission to close the digital information gap may serve to redress this important need.

The study by Bleakley and colleagues (2016) regarding the phenomenon of internet addiction shows that for adolescents who have unsupportive families and problems with social adjustment, the 24/7 lure of the internet may be difficult to resist. Youth with impulse control or attention problems are more likely to overuse the internet for either escape (game playing) or attempts to connect with others (social networking). As the review by Mills (2016) also suggested, these youth are unlikely to benefit from their retreat to the online world. Given the similarities in risk factors and our growing understanding of addictive personalities that move from one "high" to another, it would be interesting to examine whether drug dependence declines with the increase in overuse of interactive media.

Adolescent behavior is strongly influenced by peer networks. The effects of peer involvement in bullying, drug use, and risky sexual behavior have long been observed in the offline world. It is no surprise that such problems have migrated online. The reviews by Stevens and colleagues (2016) and Edwards and colleagues (2016) highlight how youth of color in the US use some social media, such as Twitter and Instagram, more than others, and how more needs to be known about the effects of online communication in these communities. The concept of a digital neighborhood suggested by Stevens et al. (2016) invites consideration of how the online world may both mirror and deviate from what has traditionally occurred offline. Of particular importance, the ability to reach such networks efficiently online opens the possibility of intervening to reduce harmful and enhance helpful peer effects.

Consistent with this opportunity, Moreno and colleagues (2016) present an interesting analysis of the various uses that social media afford for youth, not only to communicate but also to form identities. They suggest that with greater understanding of these affordances, we may be better able to develop mechanisms that protect youth from the potentially harmful peer effects that can occur online.

It is particularly concerning that advertisers have found ways to leverage adolescent engagement with the influential power of digital media to market potentially unhealthy products, such as alcohol, tobacco, and high energy-low nutrition food (Dunlop et al., 2016). These trends call for greater efforts to restrict this marketing or to counteract it with social marketing as has been conducted in traditional media.

Perhaps the most direct link between digital communication and potential harm to adolescents is the concerning evidence on texting while driving (Delgado, Wanner, \& McDonald, 2016). While the digital age has introduced smartphones, global positioning systems (GPS), and digital screen entertainment in cars, all of which can distract while driving, greater digital connectivity between adolescents may actually have reduced their need to drive. Although obtaining a driver's license has been a traditional adolescent rite of passage, adolescents can now connect and socialize with the swipe of a finger. While car manufacturers advertise that their vehicles are more connected and feature more screens, the risks of distracted driving, whether due to texting, using GPS, or tuning the radio, are elevated. Public health efforts to make the driver less distracted while driving are surely an agenda item for the future.

There is no question that today's adolescents are growing up in an environment so different from that of their parents as to be almost unrecognizable. It is certainly changing the way that they learn, communicate, and socialize. Time will tell if their brains are developing differently due to the transformed psychosocial environment in which they are embedded. But at this time, there is scant evidence that the digital revolution has placed them at increased overall health risk.

There are concerns, nevertheless, that should be taken seriously. Today's youth may be the first generation in history with a lower life expectancy than their parents (Olshansky et al., 2005), and some educators' have suggested that easy access to communication and information has impeded the development of inperson communication (e.g., Turkle, 2015) and reflective thinking (e.g., Carr, 2010). What we must be cautious about is the connections that we draw. Just because we may see positive and negative changes in behavior and health risk during the digital revolution does not mean that they are caused or contributed to by digital connectivity. Health outcomes in many of the traditional areas of concern are actually improving, as we have seen, but we must remain alert for similar problems emerging in areas where we are not yet looking. Human nature has not changed-we will make the same mistakes as we always have-but the outcomes of those mistakes may be different in the digital age.

In conclusion, despite areas of concern, there is also reason for optimism. Ubiquitous and affordable digital connectivity is giving adolescents greater freedom and more opportunities to exert their independence and autonomy. Adolescents today have greater access to information about their bodies, their selves, and the world in which they are living, all of which may lead to 
effects not seen in their predecessors. It is what they do with this enhanced connectivity that will most powerfully influence their health and wellbeing.

\section{Conflict of Interests}

The authors declare no conflict of interests.

\section{References}

Bleakley, A., Ellithorpe, M., \& Romer, D. (2016). The role of parents in problematic internet use among US adolescents. Media and Communication, 4(3), 24-34.

Borzekowski, D. L., Schenk, S., Wilson, J. L., \& Peebles, R. (2010). e-ana and e-mia: A content analysis of proeating disorder web sites. American Journal of Public Health, 100(8), 1526-1534.

Carr, N. (2010). The shallows: What the Internet is doing to our brains. New York: W. W. Norton \& Company.

Centers for Disease Control and Prevention. (2016). Injury prevention and control: Data and statistics. Retrieved from www.cdc.gov/injury/wisqars

Curtin, S. C., Warner, M., \& Hedegaard, H. (2016). Increase in suicide in the United States, 1999-2014. (NCHS Data Brief No. 241). Hyattsville, MD: National Center for Health Statistics.

Delgado, M. K., Wanner, K., \& McDonald, C. (2016). Adolescent cellphone use while driving: $A$ review of the literature and promising future directions for prevention. Media and Communication, 4(3), 79-89.

Dunlop, S. M., Freeman, B., \& Jones, S. C. (2016). Marketing to youth in the digital age: The promotion of unhealthy products and health promoting behaviours on social media. Media and Communication, 4(3), 35-49.

Dunlop, S., More, E., \& Romer, D. (2011). Where do youth learn about suicide on the Internet, and what influence does this have on suicidal ideation? The Journal of Child Psychology and Psychiatry, 52(10), 1073-1080. doi:10.1111/j.1469-7610.2011.02416.x

Edwards, L., Kontostathis, A., \& Fisher, C. (2016). Race, cyberbullying and mental health: A review of the literature. Media and Communication, 4(3), 71-78.

George, M. J., \& Odgers, C. L. (2015). Seven fears and the science of how mobile technologies may be influencing adolescents in the digital age. Perspectives in Psychological Science, 10(6), 832-851. doi:10.1177/1745 691615596788

Hagell, A., Coleman, J., \& Brooks, F. (2015). Key data on adolescence 2015. London, UK: Association for Young People's Health. Retrieved from at http:/www. youngpeopleshealth.org.uk

Johnston, L. D., O'Malley, P. M., Miech, R. A., Bachman, J. G., \& Schulenberg, J. E. (2016). Monitoring the fu- ture: National survey results on drug use, 1975-2015: Overview, key findings on adolescent drug use. Ann Arbor, MI: Institute for Social Research, University of Michigan.

Mills, K. M. (2016). Possible effects of internet use on cognitive development in adolescence. Media and Communication, 4(3), 4-12.

Moreno, M. A., D'Angelo, J., \& Whitehill, J. (2016). Social media and alcohol: Summary of research, intervention ideas and future study directions. Media and Communication, 4(3), 50-59.

Office of Adolescent Health (2016). Trends in teen pregnancy and childbearing. US Office of Adolescent Health. Retrieved from http://www.hhs.gov/ash/oah /adolescent-health-topics/reproductive-health/teenpregnancy/trends.html

Olshansky, S. J., Passaro, D. J., Hershow, R. C., Layden, J., Carnes, B. A., Brody, J., . . . \& Ludwig, D. S. (2005). A potential decline in life expectancy in the United States in the 21st century. New England Journal of Medicine, 352(11), 1138-1145.

Peebles, R., Harrison, S., McCown, K., Wilson, J., Borzekowski, D., \& Lock, J. (2012). 101. Voices of pro-Ana and pro-Mia: A qualitative analysis of reasons for entering and continuing pro-eating disorder website usage. Journal of Adolescent Health, 50(2), S62.

Pople, L., Rees, G., Main, G., \& Bradshaw, J. (2015). The good childhood report. London, UK: The Children's Society. Retrieved from: http://www.childrenssocie ty.org.uk/what-we-do/research/the-good-childhoodreport-2015

Rattan, A., \& Ambady, N. (2014). How "it gets better" effectively communicating support to targets of prejudice. Personality and Social Psychology Bulletin, 40(5), 555-566.

Stevens, R., Dunaev, J., Malvern, E., Bleakley, A., \& Hull, S. (2016). Social media in the sexual lives of African American and Latino youth: Challenges and opportunities in the digital neighborhood. Media and Communication, 4(3), 60-70.

Tropiano, S. (2014). A safe and supportive environment: LGBTQ youth and social media. In Queer youth and media cultures (pp. 46-62). London, UK: Palgrave Macmillan UK.

Turkle, S. (2015). Reclaiming conversation: The power of talk in a digital age. New York: Penguin Press.

Wartella, E., Rideout, V., Montague, H., Beaudoin-Ryan, L., \& Lauricella, A. (2016). Teens, health and technology: A national survey. Media and Communication, 4(3), 13-23.

Wilson, J. L., Peebles, R., Hardy, K. K., \& Litt, I. F. (2006). Surfing for thinness: A pilot study of pro-eating disorder web site usage in adolescents with eating disorders. Pediatrics, 118(6), e1635-e1643. 


\section{About the Authors}

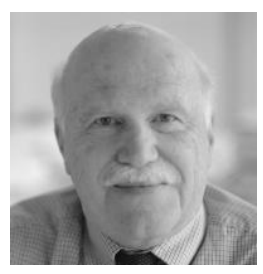

\section{Dr. Daniel Romer}

Daniel Romer, PhD, is the Director of Research at the Annenberg Public Policy Center of the University of Pennsylvania. His research focuses on policy relevant effects of the media and other social influences on the behavioral and mental health of adolescents.

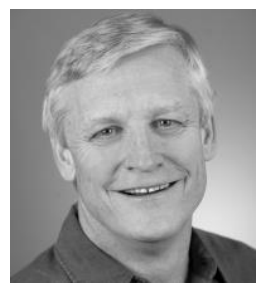

\section{Dr. Michael Rich}

Michael Rich (MD, MPH, FAAP, FSAHM) is Founder and Director of the Center on Media and Child Health, Associate Professor at Harvard Medical School and Harvard School of Public Health. As Director of the Center on Media and Child Health at Boston Children's Hospital, Dr. Rich combines his creative experience with rigorous scientific evidence about the powerful positive and negative effects of media to advise pediatricians and parents how to use media in ways that optimize child development. 